\title{
Use of a voluntary testing program to study the spatial epidemiology of Johne's disease affecting dairy herds in Minnesota: a cross sectional study
}

\author{
K. S. T. Kanankege ${ }^{1 *}$ D, G. Machado ${ }^{2}$, L. Zhang ${ }^{3}$, B. Dokkebakken ${ }^{4}$, V. Schumann ${ }^{4}$, S. J. Wells ${ }^{1}$, A. M. Perez ${ }^{1}$ and
} J. Alvarez ${ }^{5}$

\begin{abstract}
Background: One of the key steps in the management of chronic diseases in animals including Johne's disease (JD), caused by Mycobacterium avium subsp. paratuberculosis (MAP), is the ability to track disease incidence over space and time. JD surveillance in the U.S. dairy cattle is challenging due to lack of regulatory requirements, imperfect diagnostic tests, and associated expenses, including time and labor. An alternative approach is to use voluntary testing programs. Here, data from a voluntary JD testing program, conducted by the Minnesota Dairy Herd Improvement Association, were used to: a) explore whether such a program provides representative information on JD-prevalence in Minnesota dairy herds, b) estimate JD distribution, and, c) identify herd and environmental factors associated with finding JD-positive cows. Milk samples $(n=70,809)$ collected from 54,652 unique cows from 600 Minnesota dairy herds between November 2014 and April 2017 were tested using a MAP antibody ELISA. Participant representativeness was assessed by comparing the number of JD-tested herds with the number of herds required to estimate the true disease prevalence per county based on official statistics from the National Agricultural Statistical Services. Multivariable logistic regression models, with and without spatial dependence between observations, were then used to investigate the association between herd status to JD (positive/negative), as indicated by milk ELISA results, and available covariates at the herd level.

Results: Within the study population, at least one test-positive cow was found in 414 of 600 (69\%) herds. Results indicated that large herds that test frequently and herds located in loamy or silt soils are more likely to have at least one MAP test-positive cow. After adjusting for herd size, testing frequency, and soil type, there was no spatial dependence in JD risk between neighboring dairies within 5 to $20 \mathrm{~km}$. Furthermore, the importance of collecting data on herd management, feed, and biosecurity for insightful interpretations was recognized. The study suggested that, although limited, the voluntary testing database may support monitoring JD status.
\end{abstract}

Conclusions: Results presented here help elucidate the spatial characteristics of JD in Minnesota and the study may ultimately contribute to the design and implementation of surveillance programs for the disease.

Keywords: Paratuberculosis, Milk ELISA, Spatial epidemiology, CAR model, Regression, Passive surveillance

\footnotetext{
* Correspondence: kanan009@umn.edu

${ }^{1}$ Department of Population Medicine, College of VeterinaryMedicine,

University of Minnesota, 1365, Gortner Avenue, St. Paul, MN 55108, USA

Full list of author information is available at the end of the article
}

(c) The Author(s). 2019 Open Access This article is distributed under the terms of the Creative Commons Attribution 4.0 International License (http://creativecommons.org/licenses/by/4.0/), which permits unrestricted use, distribution, and reproduction in any medium, provided you give appropriate credit to the original author(s) and the source, provide a link to the Creative Commons license, and indicate if changes were made. The Creative Commons Public Domain Dedication waiver (http://creativecommons.org/publicdomain/zero/1.0/) applies to the data made available in this article, unless otherwise stated. 


\section{Background}

Johne's disease (JD) is a chronic, debilitating enteritis that affects ruminants and is caused by infection with Mycobacterium avium subsp. paratuberculosis (MAP) [1]. Financial losses due to JD in the U.S. dairy industry have been estimated to range between $\$ 200$ to 250 million USD annually [2]. Reduced milk production and quality due to reduced fat and protein content, increased premature mortality, weight loss, early culling, costs of testing and control, and reduced slaughter value are among the negative impacts of JD [3-6]. In addition, although not confirmed, the potential link between MAP and the development of Crohn's disease in humans further increases the hypothetical importance of JD [7]. A recent review highlighted that the global prevalence of JD is underestimated and setting objectives for surveillance and control measures is much needed [8].

The management and control of a chronic disease such as JD in a proactive and organized manner is challenging in the U.S. due to lack of regulatory requirements for testing [9], imperfect diagnostic tests [10], long-term survival of the pathogen outside the host [11], multiple routes of transmission, and the cost and labor necessary for long-term disease tracking [12].

JD is widespread in the U. S, and herd prevalence has been estimated as $60.7 \%$ in Midwestern U.S. dairies [13] and $91.1 \%$ nationally [14]. However, JD control is voluntary in the US and therefore testing for JD is not mandatory [9], which limits the availability of data and resources to monitor the disease. Studies suggest that limited adoption and compliance with JD testing and control strategies in dairy farms is a result of a) the chronic nature of the disease progression, therefore, the absence of the "cues-to-action" [15], b) the farmers' perception of the limited cost-effectiveness of the herd control measures [16], and c) not perceiving JD as a "hot topic" during communications with other farmers and veterinarians [16].

Due to the lack of official disease monitoring, a common alternative for evaluating the epidemiological status of JD in a region is the use of data from voluntary testing programs, such as those collected by the Minnesota Dairy Herd Improvement Association (MNDHIA). Minnesota, a Midwestern state of the U.S., has nearly 460,000 dairy cattle and is among the top ten dairy states, 6th in terms of milk cow numbers and 8th in dairy herd numbers, per 2016 statistics available from the National Agricultural Statistics Services (NASS) $[17,18]$. A proportion of Minnesota dairy farms utilize the services of MNDHIA, a member of the National Dairy Herd Improvement Association who provide a testing and production recordkeeping service to U.S. dairy farms (http://www.dhia.org/members. asp). However, it is unknown if data collected by the MNDHIA is useful as a passive surveillance tool to monitor JD in Minnesota.
The objectives of the study here were to a) test whether the voluntary JD testing program conducted by the MNDHIA can provide representative information on the prevalence of JD in dairy herds in Minnesota, b) estimate the JD distribution in Minnesota using data from the MNDHIA voluntary JD testing program, and c) identify possible herd and environmental variables associated with increased risk of having JD milk ELISA testpositive cows, using the available data. We hypothesized that results from the voluntary JD program might be used to evaluate JD status in an area and inform management decisions made by the testing agencies, veterinarians, and dairy producers. In evaluating the use of the MNDHIA database as a passive surveillance tool, our overarching objective was to generate evidence that could influence management decisions by recognizing modifiable factors to reduce the JD risk at the individual, herd, and regional levels. Results could therefore be useful in the design and implementation of surveillance programs for the U.S. dairy industry.

\section{Results}

\section{Spatial representativeness}

During the 2.5-year study period, 600/4746 (13\%) dairy herds in Minnesota tested at least once for JD at MNDHIA laboratories, representing 18.7\% (600/3210) of the licensed dairy herds in Minnesota with permits to ship milk for human consumption [17]. Figure 1 depicts the number of MNDHIA sampled dairy herds by county, the minimum required number of herds to estimate a true JD prevalence, and the number of dairy herds listed in the 2012 NASS Census of Agriculture (by terciles). We observed that the distribution of the MNDHIA participants included in this study mirrors the pattern of the milk cow herds included in the USDA NASS 2012 report (Fig. 1). Nevertheless, the minimum sample size required to estimate disease prevalence was not attained in any Minnesota county except Ramsey (where both the appropriate and observed sample sizes were 1 ).

\section{Descriptive statistics and spatial pattern recognition}

The apparent herd-level prevalence of MAP, based on having $1+$ cows with a positive milk ELISA, was $69 \%$ (414/600). The MNDHIA herds in this study included both small $(<100$ cows, $n=332)$ and large $(\geq 100$ cows, $n=268)$ dairies. Figure 2 illustrates the Getis ord $\mathrm{Gi}^{*}$ local test results for JD status and the covariates in the geographical space According to the Getis Ord $\mathrm{Gi}^{*}$ analysis, we concluded that a certain risk of JD infection was present in herds throughout Minnesota, although herds in the southeastern corner were more likely to be JD milk ELISA test-positive compared to the herds in the northcentral region (Fig. 2: Panel a). The herd size of the study population showed a similar pattern where 


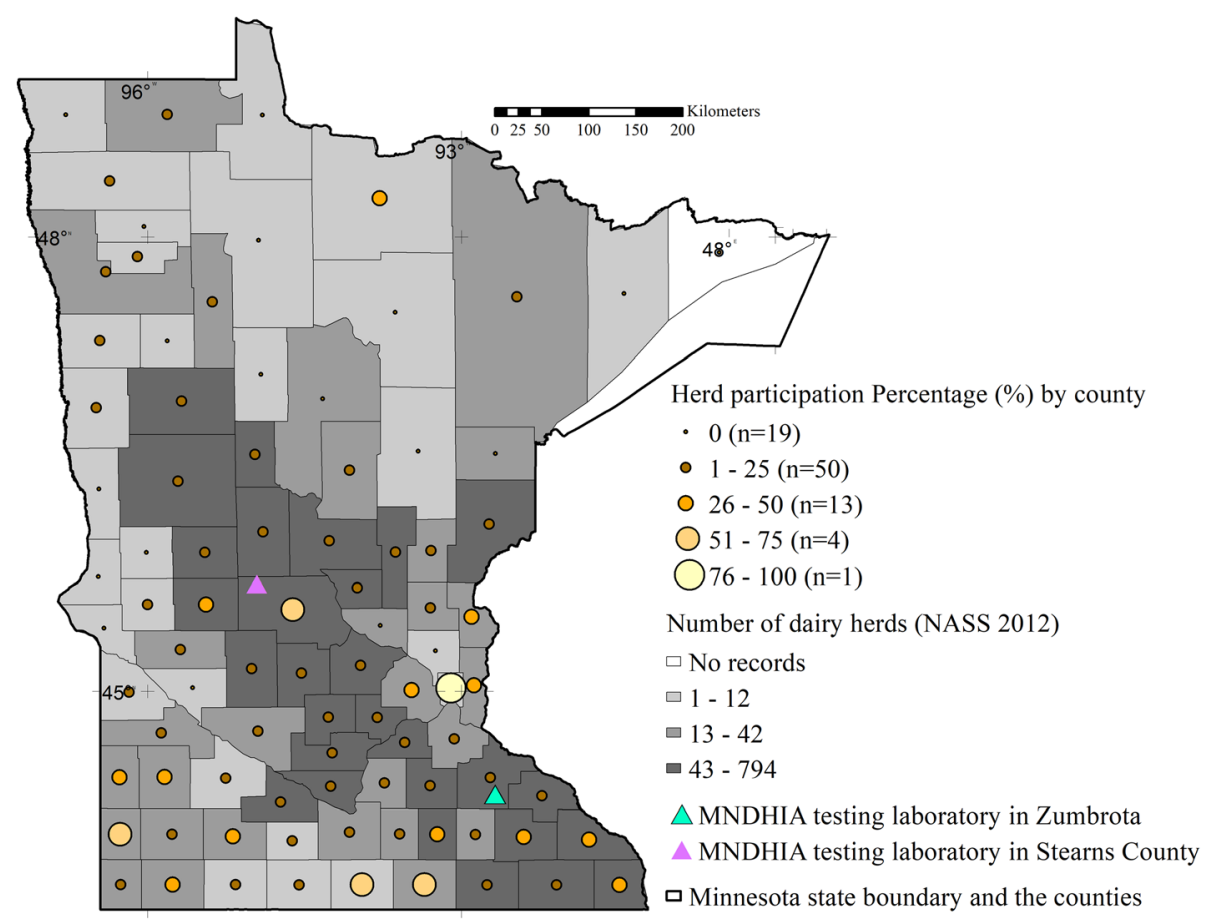

Fig. 1 The participation of study herds as a percentage of the ideal sample size, by county, is summarised with the graduated symbols. The Minnesota Dairy Herd Improvement Association testing laboratories are illustrated with triangles. The background colors in grey indicates the number of dairy herds in each county, based on 2012 census of the National Agricultural Statistics Service [18]. Map depicted here was generated as part of the current study

larger herds were located in the southeastern corner of the state, while smaller herds were in the northcentral region (Fig. 2: Panel b). We observed no spatial pattern in the testing frequency (Fig. 2: Panel c). Spatial patterns were observed for many of the remaining covariates: soil $\mathrm{pH}$, soil type (texture), soil hydrologic characteristics (runoff potential), and agroecological characteristics (Fig. 2). The soil $\mathrm{pH}$ in Western Minnesota contained predominantly alkaline soils. However, the soil type (texture), hydrologic soil types, and agroecological characteristics demonstrated intricate patterns of spatial distribution. According to the Cramer's V, none of the covariates were strongly associated with each other.

\section{Classification of JD status}

Based on the appropriate number, i.e. minimum sample size per herd (Table 2) criterion, we observed 437/600 (72.83\%) herds that had tested an appropriate number of cows during the study period. Of those 437 herds, 186 herds (31\%) had no test-positive cows. As mentioned above, all other herds had at least one positive cow (414/ $600 ; 69 \%)$. Although the study presented here considered the entire study period, the suggested minimum sample sizes listed in Table 2 are the number of cows to be tested at each testing cycle.

\section{Regression results}

Herd size, testing frequency, and soil type (texture) were retained in the final multivariable model (Table 3). Herd turnover rates were available only from 454/600 (76\%) herds and the association between JD status and herd turnover rate was not statistically significant in the univariate analysis (Table 3), therefore, excluded from the final multivariable model. The Moran's I and Getis Ord $\mathrm{Gi}^{*}$ statistics indicated that there was no spatial autocorrelation in the regression residuals $(p$ value $>0.05$ ). Similarly, results of the fitted CAR model suggested that the spatial dependence for dairy herds located between 5 and $20 \mathrm{~km}$ was not significant after adjusting for the covariates, and its AIC value was higher than that of the model without the spatial component (Additional file 2: Table S2). The spatial correlation parameter of the CAR model $(\lambda)$ was not significantly different from zero for any of the distance thresholds considered (Table 3).

\section{Discussion}

This study suggests the use of an existing voluntary testing program as a passive surveillance system to track JD in Minnesota. We demonstrated that the MNDHIA voluntary testing program may be a useful source to investigate the JD status of Minnesota dairies, with program 


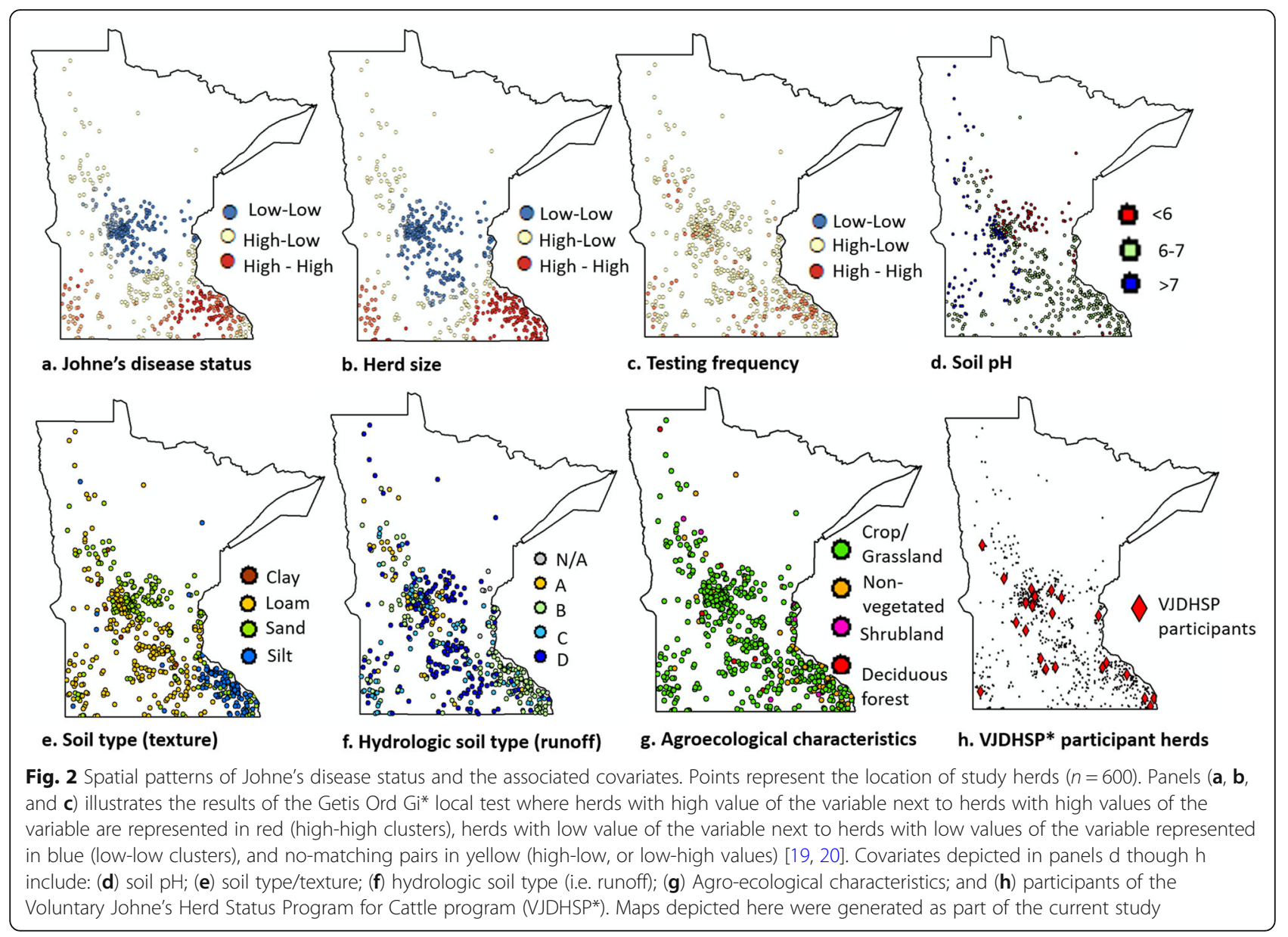

participants in 2014-2017 representing 13\% of the dairy herds across Minnesota and coming from areas with both high and low density of dairy farms. Even though county-level JD herd prevalence could not be reliably estimated because the required sample sizes were not achieved in most counties, we were able to estimate the herd-level JD status for the study area as $69 \%$, as 414 of the 600 herds had at least one cow tested-positive for JD milk ELISA. As per the epidemiological factor analysis, the most important epidemiological factors contributing to the JD status of a herd were herd size, testing frequency, and soil type, i.e. texture. We did not observe spatial dependence of the residuals of the regression model indicating that the observation of similar characteristics in JD status in the participant dairy herds were explained by the three covariates, namely, herd size, testing frequency, and soil type/texture. These results will be used to inform the potential use of the database as a surveillance tool and to suggest improvements in JD testing program conducted by MNDHIA.

JD positive herds were distributed throughout Minnesota, although herds in the southern region were more likely to be JD milk ELISA test-positive compared to herds in the north-central region (Fig. 2: Panel a). Interestingly, the herd size of the study population showed a comparable pattern, with larger herds more likely in the southern region compared to smaller herds in the northcentral region of the state (Fig. 2: Panel b). A similar observation where herd size was not evenly distributed in space, with larger herds being preferentially distributed in certain areas, was also found among participants in a Danish JD control program [21].

The herds located on silt, loam, or clay soils were more likely to be JD positive compared to the herds located on sandy soils. This observation contradicts early studies in the Midwest [22], which found that high silt content was associated with reduced detection of JD. However, studies by Dhand et al. [23] and Salgado et al. [24] described the potentially higher likelihood of detecting JD on loamy and clay soils, respectively. This survival of MAP on loamy soil was experimentally observed by Salgado et al. [24], which concluded that MAP tends to migrate slower through loamy soils compared to sandy soils and thus loamy soils may have MAP contaminated upper soil layers and pasture. Furthermore, according to Salgado et al. [24], in addition to soil type, the amount 
of rainfall and the soil $\mathrm{pH}$ also play an important role in the fate of MAP in the environment. Soil hydrologic characteristics and $\mathrm{pH}$ were not included in the final model, but it is worthwhile to acknowledge that soil texture, $\mathrm{pH}$, and hydrologic characteristics are interconnected [25] and further analysis is needed to understand the association of soil features and the persistence of MAP in manure contaminated environments [26].

Some of the limitations associated with this study include the limited generalizability of the results because MNDHIA data represents a purposive, non-random proportion of dairy herds in Minnesota. Moreover, the lack of information on herd characteristics other than herd size and testing frequency is another limitation that should be considered when interpreting the results. A more insightful interpretation requires herd management details including maternity pen management, which cows were chosen for testing for JD (high-risk cows or cows that were being sold), and the management decisions towards JD positive cows [27]. Although the long-term survival of MAP in loamy or clay soils was suggested in other studies [23], we acknowledge that additional information on the access of cattle to pastures would be necessary to establish a causal relationship between soil type and MAP exposure. Other potential routes of exposure through forages originated from other locations or grazing on pasture lands in different geographical areas such as rented pasture lands located elsewhere would certainly affect this interpretation. When data arise from imperfect surveillance systems, the interpretation of results must be done with caution because the covariates can be related either to the occurrence of the disease or to the efficiency of the data collection system [28].

Although MNDHIA does not currently offer a control program, through this study we recognized opportunities to improve the MNDHIA database to be used as a passive surveillance tool. These opportunities include: the determination of the number of herds to be sampled to establish the prevalence of JD in Minnesota, the determination of the number of animals to be sampled from each herd to ensure a reliable evaluation of its JD status (positive/negative), ensuring that farmers provide accurate farm location information, and regularly collecting herd-level information on other relevant factors such as biosecurity measures to facilitate a better assessment of JD status/risk. Moreover, having the disease and underlying factors collected frequently over the time would facilitate conducting spatiotemporal analysis and enable facilitate making temporal confidence of "disease free zones" instead of static estimates generated through a cross-sectional analysis.

A JD surveillance program would be costly to establish and a voluntary testing database could be preferred for monitoring endemic pathogens causing chronic diseases like MAP. Thus, the strength of using MNDHIA data as a source is that there are 16National Dairy Herd Improvement (DHI) Association laboratories across the U.S. (http://www.dhia.org/members.asp) and their network already acts as a record keeping system for dairy farms. Having a system to evaluate the JD status in a region would benefit the dairy industry in multiple ways, such as recognizing the differences between participant and non-participant dairy farms in the voluntary testing programs, understanding underlying risk factors and covariates in the neighborhoods, and eventually recognizing disease-free areas [6]. Moreover, records available from DHI and the Council of Dairy Cattle Breeding (https://queries.uscdcb.com/) together would have been a useful system to trace the movements/transfers or termination of individual cows, which could facilitate further investigations of how cattle movement play a role in the JD transmission. However, it is important to recognize that the choice to test for JD may not necessarily overlap temporally to make a causal association between cow transfers and JD.

Participation in voluntary testing and control programs varies due to multiple factors such as: a) farmers' belief in the importance of JD [16], b) farmers' belief in control and prevention strategies including the investment of time and resources [16], and c) availability of the testing facilities and trained personnel to conduct testing at convenience $[29,30]$. An examination of the reasons why dairy farmers choose to test, or not, for JD status exceeded the scope of this study, although such assessment may be of interest in assessing the value of voluntary testing and control programs. This study elucidates the evaluation of JD at herd and regional level using available data. The individual-level data analysis of the same dataset was presented elsewhere [31].

\section{Conclusion}

In summary, results reported here suggest that a routinely generated database obtained from a voluntary testing program can be used as a passive surveillance tool to monitor the infection status and epidemiological determinants of JD in a region. However, because the risk of introduction may always be present, successful prevention and control of JD depends on ongoing willingness to continue funding surveillance and research on the disease by both animal health authorities and the support from the community and stakeholders of livestock industry [32, 33].

\section{Methods \\ Data}

Data from the voluntary JD testing program conducted by the MNDHIA were collected through a 2.5-year 
period, between November 1st, 2014 and April 30th, 2017. Although there were records from 723 JD testing herds, 123 herds were excluded from the study (Additional file 1: Figure S1). The reasons for exclusions were: herds located outside Minnesota; herds without location information, or herds that did not test the minimum number of cows required for the study, as explained below.

Milk samples $(n=70,809)$ collected from 54,652 unique cows from 600 Minnesota dairy herds were included in the study. Samples were analyzed using the IDEXX MAP Enzyme-Linked Immunosorbent Assay (ELISA) (IDEXX Laboratories, Inc., Maine, USA) for detection of antibodies against MAP in milk. Some herds (208/600; $35 \%)$ were tested only once during the 2.5 -year study period. The median number of times a herd was tested was 2 (interquartile range between 1 and 11).

To identify relevant herd and environmental factors associated with JD risk at the herd level, the scientific databases 'Web of Science' and 'PubMed' were queried to find publications using the following search string: 'Johne's disease,' AND 'Mycobacterium avium subsp. paratuberculosis,' AND 'dairy cattle,' AND 'risk factors'. Reviews published in peer-reviewed journals in English language were selected, and reviews on human Crohn's disease were excluded. A total of seven reviews published between 2001 and 2017 on JD [32, 34-39] were used to identify the most commonly recognized JD risk factors in North American dairy farms. Reviews were then examined for identification of relevant risk factors for North America, and primary articles cited were used for identification of the variables to be considered in this study (Table 1). Due to unavailability of relevant data in our dataset, the following herd features were excluded from analysis: manure management, immediate culling of JD positive cows, management of the maternity pens and calves, and maintaining closed herd or purchasing animals from farms with improved management practices to control JD [12].
According to the published literature, herd size, testing frequency, and geographical region are associated with JD [21, 29]. Information on those three variables was extracted from the MNDHIA database. Data on herd size and herd turnover rates (454/600 herds) were available in the form of snapshots at the beginning of 2014, 2015, 2016, and 2017. Herd turnover rate calculations were performed by MNDHIA, based on the recommendations by Fetrow et al. [45]. Both herd sizes and herd turnover rates were averaged across the years for this crosssectional analysis. Farm addresses were verified and geocoded using ArcMap version 10.3.4 [46]. Because the spatial dependence of JD risk has been described for neighboring farms [44], the possible existence of a spatial pattern in the risk of JD for neighboring farms located within 5 through $20 \mathrm{~km}$ was accounted for in the analyses.

The voluntary participation in JD control programs has also been described as a factor associated with JD status in a farm [30, 47]. In the absence of data from a control program, information on whether farms included in this study were currently participating in the Voluntary Johne's Disease Herd Status Program for Cattle program (VJDSHP) was retrieved from the Minnesota Board of Animal Health $[9,29]$. VJDSHP was introduced by USDA APHIS in 2002 as a gradual process which allows to recognize herds with low JD prevalence or free from the disease [48, 49]. As of 2017, among the study population, 24/600 (4\%) herds were part of the Voluntary Johne's Disease Herd Status Program (VJDHSP).

Layers of soil pH and soil type in Minnesota were obtained from the Natural Resource Conservation Services of the United States Department of Agriculture (USDA) $[25,50,51]$. The hydrologic soils data were used to estimate the runoff potential of the soils, using the Hydrologic Soil map available from the Web Soil Survey [52]. Because of the scarcity of accurate data, soil iron content was not considered in the study. Information on agroecological biome features such as grassland, shrubland,

Table 1 Herd demographic factors and environmental factors associated with JD in North American dairy cattle, according to the published literature

\begin{tabular}{lll}
\hline & Covariates & Reference \\
\hline 1 & Herd size & {$[38-40]$} \\
2 & Testing frequency & {$[29]$} \\
3 & Soil type (texture) & {$[22]$} \\
4 & Soil pH & {$[41,42]$} \\
5 & Soil hydrologic characteristics i.e. run-off potential & {$[22,43]$} \\
6 & Agroecological zone (Montane/Boreal forest/Grassland/Parkland) & {$[39]$} \\
7 & Participating the USDA Voluntary Johne's Disease Herd Status Program i.e. VJDHSP $(n=24)$ & {$[9,30]$} \\
8 & Spatial dependence: Presence of neighboring dairy farms & {$[44]$} \\
\hline
\end{tabular}


Table 2 Minimum sample sizes required to estimate freedom from Johne's Disease (JD) at the herd level, using an imperfect test and adjusting for a finite population calculated using the AusVet EpiTool Epidemiological calculator (URL: http://epitools.ausvet.com. au)

\begin{tabular}{ll}
\hline Herd size (number of cows) & Sample size $^{\text {a }}$ \\
\hline $5-20$ & N/A (Recommendation: Same as herd size) \\
$21-25$ & 20 \\
$26-40$ & 24 \\
$41-55$ & 25 \\
$56-65$ & 26 \\
$66-80$ & 27 \\
$81-95$ & 28 \\
$96-100$ & 29 \\
$101-250$ & 30 \\
$>251$ & 31
\end{tabular}

${ }^{\mathrm{a}}$ Assumptions: a) design prevalence, i.e. expected within herd prevalence $=10 \%$, b) sensitivity of the diagnostic test of $52 \%$, and c) expected number of test infected cows in a herd is a product of herd size and the design prevalence

forest, and cropland were obtained from the Minnesota Geospatial Commons (https://gisdata.mn.gov/), which was based on remote sensing data creating the Land Cover Data Portal under the National Gap Analysis Project (GAP) [53]. The Minnesota GAP classification level 2 land-use/land-cover class code of the GAP data layer was used in the analysis (Additional file 2: Table S1).

\section{Data analysis \\ Representativeness of MNDHIA herds}

Minnesota counties were classified into terciles based on the number of NASS dairy herds present (1 to 12 , 13 to 42 , and $>43$ dairy herds per county). Counties without records for milk cow herds in the NASS 2012 statistics were excluded for this calculation $(n=1$; Cook county). To evaluate whether the study herds were representative of all Minnesota dairy herds, the number of study herds per county (tested for JD) was compared to the appropriate sample size, i.e. number of dairy herds to be sampled from each county to estimate the true herd prevalence of JD using an imperfect test and adjusting for a finite population (calculated using the AusVet EpiTool Epidemiological calculator (URL: http://epitools.ausvet.com.au) [54, 55]. Total number of herds present in each county was extracted from the National Agricultural Statistical Services (NASS) 2012 Census of dairy herds [18]. In addition, sample size calculations assumed an expected true herd prevalence of JD of $60 \%$ [13], a desired herd-level sensitivity of $70 \%$ and herd-level specificity of 70\% [56], a precision for the estimate of $+/-10 \%$ and a level of confidence of $80 \%$. The number of herds included in the MNDHIA database was then compared to the sample size required to accurately estimate prevalence.

\section{Descriptive statistics and spatial pattern recognition}

The apparent JD prevalence, the spatial distribution of JD milk ELISA test-positive farms, and the presence of spatial autocorrelation in the risk of JD and in other covariates considered were visualized and, for the latter, estimated using Morans' I and Getis Ord Gi* statistics [19, 20, 57]. Morans' I statistics measures the overall spatial autocorrelation of the herds based on both locations and value of the variable simultaneously [57]. The Getis Ord Gi* recognizes areas where the local sum of values for a given variable significantly differ from the expected location sum $[19,20]$. This statistic identifies herds with high value of the variable next to herds with high values of the variable (high-high clusters), herds with low value of the variable next to herds with low values of the variable (lowlow clusters), and no-matching pairs (high-low, or lowhigh values). Categorical variables, not suited for Getis Ord $\mathrm{Gi}^{*}$ analysis, were mapped for visualization (Fig. 2).

\section{Classification of JD status}

The output variable (herd JD status) was dichotomized as follows: 1) 'Negative herds' in which an appropriate number of unique cows were tested during the study period and were all negative (see below definition of appropriate number) and 2) 'Positive herds' in which at least one cow was tested positive on the milk ELISA test during the entire study period. The appropriate sample size to certify disease freedom in a herd, i.e. minimum required sample size per herd, using an imperfect test and adjusting for a finite population, was set for each herd using the AusVet EpiTool Epidemiological calculator (URL: http://epitools.ausvet.com.au) [54, 55]. Assumptions for the calculations were a) design prevalence, i.e. expected within-herd prevalence when infected, of $10 \%$ [58], and b) sensitivity of the diagnostic 
Table 3 Odds ratios, coefficients, and p-values of the association between epidemiological factors and herd-level Johne's disease status, based on ELISA assays performed on individual milk samples in 600 herds in Minnesota

\begin{tabular}{|c|c|c|c|c|c|c|c|}
\hline \multirow[t]{2}{*}{ Covariates } & \multirow[t]{2}{*}{$N$} & \multicolumn{2}{|l|}{ Univariable analysis } & \multicolumn{4}{|c|}{ Multivariable analysis } \\
\hline & & Odds ratio $\left(\mathrm{Cl}_{95 \%}\right)$ & $\overrightarrow{p \text {-value }}$ & $\bar{\beta}$ & S.E. & Odds ratio $\left(\mathrm{Cl}_{95 \%}\right)$ & $p$-value \\
\hline Herd size & & & $<0.001$ & & & & $<0.001$ \\
\hline 1 to $\leq 195$ & 476 & Ref & - & - & - & - & - \\
\hline 196 to $\leq 553$ & 100 & $1.67(1.39-2.02)$ & $<0.001$ & 1.58 & 0.43 & $4.84(2.20-12.27)$ & $<0.001$ \\
\hline 554 to 1929 & 24 & $13.74(2.86-246.87)$ & 0.011 & 1.54 & 1.08 & $4.67(0.83-88.29)$ & 0.153 \\
\hline Testing frequency & & & $<0.001$ & & & & $<0.001$ \\
\hline 1 & 208 & Ref & - & - & - & - & - \\
\hline$>1$ to $\leq 5$ & 208 & $3.04(2.03-4.57)$ & $<0.001$ & 1.03 & 0.21 & $2.81(1.86-4.29)$ & $<0.001$ \\
\hline 6 to $\leq 20$ & 80 & $13.15(6.16-32.64)$ & $<0.001$ & 2.48 & 0.43 & 11.85(5.44-29.82) & $<0.001$ \\
\hline 21 to 30 & 104 & 64.30(19.64-396.39) & $<0.001$ & 3.77 & 0.73 & $43.34(13.00-269.33)$ & $<0.001$ \\
\hline Soil type (texture) & & & $<0.001$ & & & & 0.017 \\
\hline Sand & 189 & Ref & - & - & - & - & - \\
\hline Silt & 115 & $2.87(1.69-5.01)$ & $<0.001$ & 0.63 & 0.32 & $1.88(1.01-3.54)$ & 0.047 \\
\hline Loam & 290 & $1.79(1.21-2.63)$ & 0.003 & 0.63 & 0.22 & $1.88(1.21-2.93)$ & 0.005 \\
\hline Clay & 6 & $3.59(0.56-69.51)$ & 0.25 & 1.62 & 1.15 & $5.04(0.68-102.54)$ & 0.162 \\
\hline Herd turnover rate & & & 0.164 & & & & \\
\hline 18 to 37 & 192 & Ref & & & & & \\
\hline 38 to 50 & 236 & $1.02(0.93-1.11)$ & 0.698 & & & & \\
\hline 51 to 78 & 26 & $0.79(0.66-0.95)$ & 0.014 & & & & \\
\hline Soil pH & & & 0.004 & & & & \\
\hline$<6.0$ & 44 & Ref & - & & & & \\
\hline 6.0 to 7.0 & 467 & $2.15(1.14-4.03)$ & 0.02 & & & & \\
\hline$>7.0$ & 89 & $2.21(1.05-4.70)$ & 0.037 & & & & \\
\hline Hydrologic soil type & & & 0.87 & & & & \\
\hline A & 57 & Ref & & & & & \\
\hline B & 205 & $1.23(0.64-2.29)$ & 0.527 & & & & \\
\hline C & 119 & $0.95(0.47-1.85)$ & 0.874 & & & & \\
\hline $\mathrm{D}$ & 211 & 0.95(0.49-1.76) & 0.872 & & & & \\
\hline Participation in VJDHSPa & & & 0.84 & & & & \\
\hline Non-participants & 576 & Ref & - & & & & \\
\hline Participants & 24 & $1.09(0.46-2.87)$ & 0.84 & & & & \\
\hline Agroecological zone & & & 0.57 & & & & \\
\hline Crop/Grassland & 534 & Ref & - & & & & \\
\hline Non-vegetated land & 52 & $0.85(0.76-0.96)$ & 0.76 & & & & \\
\hline Shrubland & 7 & $0.94(0.82-1.07)$ & 0.50 & & & & \\
\hline Deciduous Forest & 7 & $1.08(0.95-1.22)$ & 0.50 & & & & \\
\hline \multicolumn{8}{|l|}{ Spatial dependence } \\
\hline $1 \mathrm{~km}$ & 0 & & & $\lambda=\Lambda$ & & & \\
\hline $5 \mathrm{~km}$ & 344 & & & $\lambda=0$ & & & 0.962 \\
\hline $10 \mathrm{~km}$ & 519 & & & $\lambda=0$ & & & 0.171 \\
\hline $15 \mathrm{~km}$ & 565 & & & $\lambda=0$ & & & 0.256 \\
\hline $20 \mathrm{~km}$ & 580 & & & $\lambda=0$ & & & 0.157 \\
\hline $109.7 \mathrm{~km}$ & 600 & & & $\lambda=-$ & & & 0.352 \\
\hline
\end{tabular}

p-values from the Likelihood Ratio Test. Spatial correlation parameter $(\lambda){ }^{a}$ VJDHSP $=$ USDA Voluntary Johne's Disease Herd Status Program for Cattle program 
test of 52\% (IDEXX Laboratories Inc., Maine, USA). Herds that tested fewer cows than the appropriate sample size and that had no positive cows were excluded from the analysis because their apparent JD disease freedom/negative state could not be reliably demonstrated.

\section{Regression analysis}

The outcome variable used in all models was the farmlevel JD milk ELISA test-status (positive, negative). The herd size, which ranged between 1 and 1929 cows, was categorized using Jenks natural breaks method [59]. Similarly, herd turnover rate was categorized into three based on Jenks natural breaks. The testing frequency per herd during the 2.5 years varied between once and 30 times, and was categorized into four classes $(1,2$ to 5,6 to 20 , and $>20$ ). Soil $\mathrm{pH}$ values ranged between 5.6 and 7.5 , and were categorized into three $(<6.0,6.0$ to 7.0 , and $>7.0$ ) groups. The soil type/texture was recategorized into four classes based on the percentage of different types of particles as clay ( $>50 \%$ clay and $\leq 50 \%$ silt), sand ( $>50 \%$ sand and $\leq 50 \%$ clay), silt ( $>50 \%$ silt and $\leq 50 \%$ sand), and loam (equal proportions of sand, silt and clay, i.e. $\leq 50 \%$ sand, $\leq 50 \%$ clay, and $\leq 50 \%$ silt), following the soil texture triangle model described elsewhere $[60,61]$. Soil hydrologic characteristics were summarized into four categories: 1) Type A with low runoff potential, 2) Type B with moderately low runoff potential, 3) Type $C$ with moderately high runoff potential, and 4) Type D with high runoff potential, when completely wet [51, 52, 61]. Agroecological biome features included four categories, namely, crop/grassland, nonvegetated land, shrubland, and deciduous forest (Additional file 2: Table S1). The VJDHSP participation status was incorporated into the model as a dichotomous variable (current participant vs. non-participant herds).

To avoid multicollinearity, a simple logistic regression was used to assess the marginal association between JD status and the covariates. The strength of the association between pairs of covariates was analyzed using Chisquare test followed by a Cramer's V test. Variables with $p$-value $<0.2$ and that were not significantly associated among them (i.e., Chi-square $p$-values $>0.05$ and Cramer's $\mathrm{V}>0.5$ ) were tested as candidate variables in the full multivariable logistic regression model. To prevent overfitting, the full model, including all possible 2-way interactions deemed biologically plausible, was subjected to backward stepwise regression based on the lowest Akaike Information Criterion (AIC) until the most parsimonious (final) model was fitted. The regression analysis was carried out using the R Statistical Software (Foundation for Statistical Computing, Vienna, Austria). For the descriptive analysis and logistic regression, we used $R$ packages 'Base' [62] and 'MASS' [63].
Evidence of spatial autocorrelation in the residuals of the final regression model was assessed using the global Morans I and local Getis Ord Gi* tests. To account for potential spatial dependence in the outcome variable, a proper conditional autoregressive model (CAR) structure was included in the model [64] using the "spdep" $\mathrm{R}$ package [65, 66]. Distances of $1 \mathrm{~km}, 5 \mathrm{~km}, 10 \mathrm{Km}, 15$ $\mathrm{km}, 20 \mathrm{~km}$ and the minimum distance between herds that guaranteed all herds had at least one neighbor were tested alternatively to define the neighborhood matrix in the CAR [67]. The isolated herds without a neighbor at each distance thresholds were assigned a lag value of zero at each model fit. The AIC values and significance of the spatial correlation parameter of the CAR model $(\lambda)$ from the regression models with and without the CAR model structure were compared to select the best model [67].

\section{Supplementary information}

Supplementary information accompanies this paper at https://doi.org/10. 1186/s12917-019-2155-7.

\section{Additional file 1: Figure S1. The study population $(n=600 ; 13 \%$ of the 4746 dairy herds in Minnesota [18] compared to the participants in the Minnesota Dairy Herd Improvement Association (MNHIA; $n=1741)$. The 600 herds here $18.7 \%$ of the licensed dairy herds in Minnesota with permits to ship milk for human consumption [17]. Between November 2014 and April 2017, there were 723 herds tested for JD at MNDHIA. Among those, 123 were excluded due to locations outside Minnesota $(\mathrm{MN})$ including lowa (IA), Wisconsin (WI), and South Dakota (SD); herds without location information; and, 3) inadequate sampling. \\ Additional file 2: Table S1. Environmental factors assessed for association with Johne's disease status in Minnesota dairy herds participating in the voluntary testing program conducted by Minnesota Dairy Herd Improvement Association. Table S2. Akike information criterion (AIC) values for the model fits.}

\section{Abbreviations}

CAR: Conditional autoregressive model; ELISA: Enzyme-Linked Immunosorbent Assay; GAP: National Gap Analysis Project; JD: Johne's disease; MAP: Mycobacterium avium subsp. paratuberculosis; MNDHIA: Minnesota Dairy Herd Improvement Association; NASS: National Agricultural Statistics Services; USDA: United States Department of Agriculture; VJDSHP: Voluntary Johne's Herd Status Program for Cattle program

\section{Acknowledgements}

We acknowledge Mr. Gregory Palace and members of the Minnesota Dairy Herd Improvement Association for their support in data collection, Prof. Jay Bell of the University of Minnesota for his inputs on soil characterization, and Dr. Julie Adamchick for the valuable suggestions and proofreading.

\section{Authors' contributions}

KSTK, GM, AP, SJW, and JA designed the study. VS and BD contributed by data collection and providing expert opinion on the interpretations. KSTK, LZ, $A P$, and JA performed the data cleaning and analysis. AP, SJW, and JA were involved in the acquisition of funding. All authors (KSTK, GM, LZ, BD, VS, SJW, $A P$, and $J A$ ) contributed to writing and revising of the manuscript. All authors (KSTK, GM, BD, VS, LZ, SJW, AP, and JA) read and approved the final version.

\section{Funding}

This study was funded in part by the Minnesota Discovery, Research, and Innovation Economy (MnDRIVE) program and Office of the Vice President for 
Research (OVPR) of the University of Minnesota. The funding body has not been directly involved in the data collection, analysis, interpretation, or the manuscript writing process.

\section{Availability of data and materials}

The datasets used during the current study is property of Minnesota Dairy Herd Improvement Association and may be available from the corresponding author on reasonable request and DHIA approvals.

\section{Ethics approval and consent to participate}

Not applicable.

\section{Consent for publication}

Not applicable.

\section{Competing interests}

The authors declare that they have no competing interests.

\section{Author details}

'Department of Population Medicine, College of VeterinaryMedicine, University of Minnesota, 1365, Gortner Avenue, St. Paul, MN 55108, USA. ${ }^{2}$ Department of Population Health and Pathobiology, College of Veterinary Medicine, North Carolina State University, Raleigh, USA. ${ }^{3}$ Division of Biostatistics, School of Public Health, University of Minnesota, Minneapolis, USA. ${ }^{4}$ Minnesota Dairy Herd Improvement Association, Buffalo, USA. ${ }^{5}$ Centro de Vigilancia Sanitaria Veterinaria (VISAVET), Departamento de Sanidad Animal, Facultad de Veterinaria, Universidad Complutense, Madrid, Spain.

Received: 27 June 2018 Accepted: 24 October 2019

Published online: 02 December 2019

\section{References}

1. Collins MT. Update on paratuberculosis: epidemiology of Johne's disease and the biology of Mycobacterium paratuberculosis. Ir Vet J. 2003;56:565-74.

2. Ott SL, Wells SJ, Wagner BA. Herd-level economic losses associated with Johne's disease on US dairy operations. Prev Vet Med. 1999;40:179-92.

3. Gonda MG, Chang YM, Shook GE, Collins MT, Kirkpatrick BW. Effect of Mycobacterium paratuberculosis infection on production, reproduction, and health traits in US Holsteins. Prev Vet Med. 2007;80:103-19.

4. Raizman EA, Fetrow J, Wells SJ, Godden SM, Oakes MJ, Vazquez G. The association between Mycobacterium avium subsp. paratuberculosis fecal shedding or clinical Johne's disease and lactation performance on two Minnesota, USA dairy farms. Prev Vet Med. 2007;78:179-95.

5. Lombard JE. Epidemiology and economics of paratuberculosis. Vet Clin North Am Food Anim Pract. 2011;27:525-35.

6. Garcia AB, Shalloo L. Invited review: the economic impact and control of paratuberculosis in cattle. J Dairy Sci. 2015;98:5019-39.

7. Waddell L, Rajic A, Stark K, McEwen SA. Mycobacterium avium sub spp. paratuberculosis detection in animals, food, water and other sources or vehicles of human exposure: a scoping review of the existing evidence. Prev Vet Med. 2016;132:32-48.

8. Whittington R, Donat $\mathrm{K}$, Weber D, Nielsen S, Eisenberg S, Arrigoni N, et al. Control of paratuberculosis: who, why and how. A review of 48 countries. BMC Vet Res. 2019;15:198. https://doi.org/10.1186/s12917-019-1943-4.

9. APHIS: United States Department of Agriculture - Animal and Plant Health Inspection Service. Disease information. Preventing Introduction of Johne's disease. Last modified: August 2015. 2015. Available from: https://www.aphis.usda.gov/aphis/ourfocus/animalhealth/animal-diseaseinformation/cattle-disease-information/sa_johnes/ct_prevent-intro. Accessed 01 Mar 2018.

10. Nielsen SS, Toft N. Ante mortem diagnosis of paratuberculosis: a review of accuracies of ELISA, interferon-gamma assay and faecal culture techniques. Vet Microbiol. 2008;129:217-35.

11. Whittington RJ, Marsh IB, Reddacliff LA. Survival of Mycobacterium avium subsp paratuberculosis in dam water and sediment. Appl Environ Microbiol. 2005;71:5304-8.

12. McKenna SLB, Keefe GP, Tiwari A, VanLeeuwen J, Barkema HW. Johne's disease in Canada part II: disease impacts, risk factors, and control programs for dairy producers. Can Vet J. 2006;47:1089-99.
13. USDA. Johne's disease on U.S. dairy operations. In: Johne's disease on U.S. dairy operations. Washington DC: Animal and Plant Health Inspection Service; 1997.

14. Lombard JE, Gardner IA, Jafarzadeh SR, Fossler CP, Harris B, Capsel RT, Wagner BA, Johnson WO. Herd-level prevalence of Mycobacterium avium subsp paratuberculosis infection in United States dairy herds in 2007. Prev Vet Med. 2013;108:234-8.

15. Benjamin LA, Fosgate GT, Ward MP, Roussel AJ, Feagin RA, Schwartz AL. Attitudes towards biosecurity practices relevant to Johne's disease control on beef cattle farms. Prev Vet Med. 2010;94:222-30.

16. Ritter C, Kwong GPS, Wolf R, Pickel C, Slomp M, Flaig J, Mason S, Adams CL, Kelton DF, Jansen J, De Buck J, Barkema HW. Factors associated with participation of Alberta dairy farmers in a voluntary, management-based Johne's disease control program. J Dairy Sci. 2015;98:7831-45.

17. NASS: National Agricultural Statistics Service. Milk Production. ISSN:19491557. 2018. Available from: http://usda.mannlib.cornell.edu/usda/nass/ MilkProd//2010s/2017/MilkProd-02-21-2017.pdf. Accessed 07 June 2017.

18. NASS: National Agricultural Statistics Service. Census of Agriculture. United States Department of Agriculture. Washington DC: Government Printing Office; 2012. Available from: https:/www.agcensus.usda.gov/Publications/2012/Full_Report/ Volume_1,_Chapter_2_US_State_Level/st99_2_011_011.pdf. Table 11. pp 343

19. Getis A, Ord JK. The analysis of spatial association by use of distance statistics. Geogr Anal. 1992;24:189-206.

20. Ord JK, Getis A. Local spatial autocorrelation statistics - distributional issues and an application. Geogr Anal. 1995;27:286-306.

21. Bihrmann K, Nielsen SS, Toft N, Ersboll AK. Spatial differences in occurrence of paratuberculosis in Danish dairy herds and in control programme participation. Prev Vet Med. 2012;103:112-9.

22. Ward MP, Perez AM. Association between soil type and paratuberculosis in cattle herds. Am J Vet Res. 2004;65:10-4.

23. Dhand NK, Eppleston J, Whittington RJ, Toribio J. Association of farm soil characteristics with ovine Johne's disease in Australia. Prev Vet Med. 2009; 89:110-20.

24. Salgado M, Collins MT, Salazar F, Kruze J, Bolske G, Soderlund R, Juste R, Sevilla IA, Biet F, Troncoso F, Alfaro M. Fate of Mycobacterium avium subsp paratuberculosis after application of contaminated dairy cattle manure to agricultural soils. Appl Environ Microbiol. 2011;77:2122-9.

25. Ditzler C, Scheffe K, Monger HC, editors. Soil Science Division Staff. Soil survey manual. USDA Handbook 18. Washington, D.C: Government Printing Office; 2017.

26. Grewal SK, Rajeev S, Sreevatsan S, Michel FC. Persistence of Mycobacterium avium subsp paratuberculosis and other zoonotic pathogens during simulated composting, manure packing, and liquid storage of dairy manure. Appl Environ Microbiol. 2006;72:565-74.

27. Whitlock RH, Rosenberger AE, Siebert M, Sweeney R. Environmental survey of Mycobacterium paratuberculosis on dairy farms with a known history of Johne's disease. Proc Annu Meet US Anim Health Assoc. 1991;95:276-80.

28. Vergne T, Paul MC, Chaengprachak W, Durand B, Gilbert M, Dufour B, Roger F, Kasemsuwan S, Grosbois V. Zero-inflated models for identifying disease risk factors when case detection is imperfect: application to highly pathogenic avian influenza H5N1 in Thailand. Prev Vet Med. 2014;114:28-36.

29. USDA-APHIS-VS: United States Department of Agriculture - Animal and Plant Health Inspection Service - Veterinary Services. Uniform Program Standards for the Voluntary Bovine Johne's Disease Control Program, APHIS 91-45-016, 2010. http://www.johnesdisease.org. Available online from: https://johnes.org/handouts/files/USDA_Program_Standards_Sept-2010.pdf. Accessed 15 Dec 2016.

30. Collins MT, Eggleston V, Manning EJB. Successful control of Johne's disease in nine dairy herds: results of a six-year field trial. J Dairy Sci. 2010;93:1638-43.

31. Machado G, Kanankege K, Schumann V, Wells S, Perez A, Alvarez J. Identifying individual animal factors associated with Mycobacterium avium subsp paratuberculosis (MAP) milk ELISA positivity in dairy cattle in the Midwest region of the United States. BMC Vet Res. 2018;14:28. https://doi. org/10.1186/s12917-018-1354-y.

32. Kennedy DJ, Benedictus G. Control of Mycobacterium avium subsp paratuberculosis infection in agricultural species. Rev. Sci. Tech. Off Int Epizoot. 2001;20:151-79.

33. Federal register 65. 2000. Available online at: https://www.aphis.usda.gov/ animal_health/animal_diseases/johnes/downloads/docket98-037-2.pdf. Accessed 20 June 2017. 
34. Tiwari A, VanLeeuwen JA, McKenna SLB, Keefe GP, Barkema HW. Johne's disease in Canada - part l: clinical symptoms, pathophysiology, diagnosis, and prevalence in dairy herds. Can Vet J. 2006;47:874-82.

35. Dore E, Pare J, Cote G, Buczinski S, Labrecque O, Roy JP, Fecteau G. Risk factors associated with transmission of Mycobacterium avium subsp paratuberculosis to calves within dairy herd: a systematic review. J Vet Intern Med. 2012;26:32-45.

36. Elliott GN, Hough RL, Avery LM, Maltin CA, Campbell CD. Environmental risk factors in the incidence of Johne's disease. Crit Rev Microbiol. 2015; 41:488-507.

37. Rangel SJ, Pare J, Dore E, Arango JC, Cote G, Buczinski S, Labrecque O, Fairbrother JH, Roy JP, Wellemans V, Fecteau G. A systematic review of risk factors associated with the introduction of Mycobacterium avium spp. paratuberculosis (MAP) into dairy herds. Can Vet J. 2015;56:169-77.

38. Wells SJ, Wagner BA. Herd-level risk factors for infection with Mycobacterium paratuberculosis in US dairies and association between familiarity of the herd manager with the disease or prior diagnosis of the disease in that herd and use of preventive measures. J Am Vet Med Assoc. 2000;216:1450-7.

39. Scott HM, Sorensen O, Wu JT, Chow EY, Manninen K. Seroprevalence of and agroecological risk factors for Mycobacterium avium subspecies paratuberculosis and Neospora caninum infection among adult beef cattle in cow-calf herds in Alberta, Canada. Can Vet J. 2007;48:397-406.

40. Pillars RB, Grooms DL, Woltanski JA, Blair E. Prevalence of Michigan dairy herds infected with Mycobacterium avium subspecies paratuberculosis as determined by environmental sampling. Prev Vet Med. 2009;89:191-6.

41. Kopecky KE. Distribution of paratuberculosis in Wisconsin, by soil regions. J Am Vet Med Assoc. 1977;170:320-4.

42. Johnson-Ifearulundu YJ, Kaneene JB. Relationship between soil type and Mycobacterium paratuberculosis. J Am Vet Med Assoc. 1997;210:1735-40.

43. Pickup RW, Rhodes G, Bull TJ, Arnott S, Sidi-Boumedine K, Hurley M, Hermon-Taylor J. Mycobacterium avium subsp paratuberculosis in lake catchments, in river water abstracted for domestic use, and in effluent from domestic sewage treatment works: diverse opportunities for environmental cycling and human exposure. Appl Environ Microbiol. 2006;72:4067-77.

44. Collins MT, Sockett DC, Goodger WJ, Conrad TA, Thomas CB, Carr DJ. Herd prevalence and geographic distribution of, and risk factors for, bovine paratuberculosis in Wisconsin. J Am Vet Med Assoc. 1994;204:636-41.

45. Fetrow J, Nordlund KV, Norman HD. Invited review: culling: nomenclature, definitions, and recommendations. J Dairy Sci. 2006;89(6):1896-905.

46. ESRI: Environmental Systems Research Institute. ArcMap Version 10.3.4. Redlands: Environmental Research Institute, Inc; 2017

47. Carter MA. Prevalence and prevention of Paratuberculosis in North America. Jpn J Vet Res. 2012;60:S9-S18.

48. USAHA: United States Animal Health Association. Proceedings of the 97th Annual Meeting of the USAHA. 1993.

49. Rideout BA, Brown ST, Davis WC, Gay JM, Giannella RA, Hines ME II, Hueston WD, Hutchinson L, et al. Committee on Diagnosis and Control of Johne's Disease Board on Agriculture and Natural Resources. Division on Earth and Life Studies. USA: National Academy of Sciences; 2003. ISBN: 0-309-56641-X, 244 pages, $6 \times 9$

50. Soil Survey Staff. Gridded Soil Survey Geographic (gSSURGO) Database for State name. United States Department of Agriculture, Natural Resources Conservation Service. 2018. (FY2018 official release). Available online at: http://datagateway.nrcs.usda.gov/. Accessed 10 Feb 2018.

51. Soil survey staff. USDA soil texture triangle classification. Based on: Davis, R. O. E., Bennett, H. H., 1927. Grouping of soils on the basis of mechanical analysis, Dep. Circ. 419, U.S. Dep. of Agric., Washington, D.C.; 2017. Available online at: https://www.nrcs.usda.gov/Internet/FSE_DOCUMENTS/stelprdb1 044818.pdf. Accessed 10 Feb 2018.

52. Soil Survey Staff. Hydrologic Soil Group. Natural Resources Conservation Service, United States Department of Agriculture. Web Soil Survey. 2018. Available online at: https://websoilsurvey.sc.egov.usda.gov/. Accessed 10 Jan 2018

53. National Gap Analysis Project. Upper Midwest Gap Analysis Program (UMGAP) of the U.S. Geological Survey. 30-meter resolution. (gapanalysis. usgs.gov). Accessed through Minnesota Geospatial commons. Available online at: ftp://ftp.gisdata.mn.gov/pub/gdrs/data/pub/us_mn_state_dnr/ biota_landcover_gap/metadata/metadata.html. Accessed 10 Jan 2018.

54. Humphry RW, Cameron A, Gunn GJ. A practical approach to calculate sample size for herd prevalence surveys. Prev Vet Med. 2004;65:173-88.
55. Thrusfield M. Veterinary Epidemiology. 3rd ed. Oxford: Blackwell Science; 2007. p. 233-4. ISBN: 978-1-405-15627-1

56. VanLeeuwen JA, Keefe GP, Tremblay R, Power C, Wichtel JJ. Seroprevalence of infection with Mycobacterium avium subspecies paratuberculosis, bovine leukemia virus, and bovine viral diarrhea virus in maritime Canada dairy cattle. Can Vet J. 2001;42:193-8.

57. Moran PAP. The interpretation of statistical maps. J Royal Stat Soc Series B. 1948;37:243-51.

58. Raizman EA, Wells SJ, Munoz-Zanzi CA, Tavornpanich S. Estimated withinherd prevalence (WHP) of Mycobacterium avium subsp paratuberculosis in a sample of Minnesota dairy herds using bacterial culture of pooled fecal samples. Can J Vet Res-Revue Canadienne De Recherche Veterinaire. 2011; 75(2):112-6.

59. Jenks GF. The data model concept in statistical mapping. Int Yearbook of Cartography. 1967:7:186-90.

60. Davis ROE, Bennett HH. Grouping of soils on the basis of mechanical analysis. Washington, D. C: Dep. Circ. 419, U.S. Dep. of Agric; 1927.

61. Weil R, Brady N. The nature and properties of soils. 15th ed. New York: Pearson Education; 2016. p. 134-222. ISBN 9780133254488

62. R Core Team. R: A language and environment for statistical computing. Vienna: R Foundation for Statistical Computing; 2017. https://www.R-project.org/.

63. Venables WN, Ripley BD. Modern Applied Statistics with S. 4th ed. New York: Springer; 2002. ISBN: 0-387-95457-0

64. Besag J. Spatial interaction and the statistical analysis of lattice systems (with discussion). J Royal Stat Soc Series B. 1974;36:192-236.

65. Bivand R, Piras G. Comparing implementations of estimation methods for spatial econometrics. J Stat Softw. 2015;63:1-36.

66. Bivand RS, Hauke J, Kossowski T. Computing the Jacobian in Gaussian spatial autoregressive models: an illustrated comparison of available methods. Geogr Anal. 2013;45:150-79.

67. Banerjee S, Carlin BP, Gelfand AE. Hierarchical modeling and analysis for spatial data. 2nd ed. Boca Raton: CRC press; 2015. p. 73-96.

\section{Publisher's Note}

Springer Nature remains neutral with regard to jurisdictional claims in published maps and institutional affiliations.

Ready to submit your research? Choose BMC and benefit from

- fast, convenient online submission

- thorough peer review by experienced researchers in your field

- rapid publication on acceptance

- support for research data, including large and complex data types

- gold Open Access which fosters wider collaboration and increased citations

- maximum visibility for your research: over $100 \mathrm{M}$ website views per year

At BMC, research is always in progress.

Learn more biomedcentral.com/submissions 